\title{
Overall Survival of Patients With Locoregional and Metastatic Breast Cancer: Is the Influence of Baseline Characteristics the Same?
}

\author{
INÊS GOMES ${ }^{1,2,3}$, PEDRO AGUIAR $^{1,3}$, ANA MIRANDA $^{4}$ and CARLA NUNES ${ }^{1,3}$ \\ ${ }^{1}$ National School of Public Health, NOVA University of Lisbon (ENSP/NOVA), Lisbon, Portugal; \\ ${ }^{2}$ Pfizer, Porto Salvo, Portugal; \\ ${ }^{3}$ Public Health Research Center, NOVA University of Lisbon, Lisbon, Portugal; \\ ${ }^{4}$ Southern Portugal Cancer Registry (ROR-Sul), \\ Instituto Português de Oncologia de Lisboa Francisco Gentil, Lisbon, Portugal
}

\begin{abstract}
Aim: To compare the overall survival (OS) of patients with locoregional and metastatic breast cancer $(B C)$ considering baseline demographic, clinical and contextual characteristics. Materials and Methods: A retrospective analysis of a cancer registry was conducted, using the Kaplan-Meier and Mantel-Cox analyses for the calculation of median OS and cumulative survival. Results: The median OS was 112 months, being longer in patients with locoregional versus those with metastatic BC at diagnosis (115 vs. 31 months, $p<0.001$ ). The cumulative survival at 1, 3 and 5 years were $94.9 \%, 85.6 \%$ and $76.5 \%$, respectively. More recent year of diagnosis [hazard ratio $(H R)=1.09]$ and age at diagnosis $(\geq 65 \mathrm{vs} .40$ years, $H R=2.79)$ and presence of metastatic disease $(H R=5.69)$ were associated with a shorter $O S$. The region of residence, morphology and topography of the tumor were also associated with survival in patients with BC. Rurality was only associated with lower survival in patients with metastatic BC. Conclusion: This study identified significant differences in the median OS of patients with locoregional and those with metastatic BC considering their baseline characteristics.
\end{abstract}

Breast cancer $(\mathrm{BC})$ is the most frequent malignant disease in women worldwide $(1,2)$, in Europe $(2,3)$ and in Portuguese women (3-9). Survival of patients with BC has expanded over time (10-16), an improvement that can be attributed to the increase in cases being diagnosed early $(11,17-20)$, screening actions (11-13, 17, 20), and treatment advances (10-12, 17, 20$22)$. The survival of patients with $\mathrm{BC}$ has also been associated

Correspondence to: Inês Gomes, National School of Public Health, Universidade NOVA de Lisboa (ENSP/NOVA), Lisbon, Portugal. Tel: +351 934968820, e-mail: ia.gomes@ensp.unl.pt

Key Words: Breast neoplasms, Portugal, survival proportion, survival analysis. with other factors such as stage $(10-14,17,20-23)$ and age at diagnosis $(4,5,6-12,14,15,16,21,24-26)$, rurality $(25,27)$, and other prognostic factors $(16,28)$ such as the histology of the tumor $(13,16,28,29)$ and tumor location $(30)$.

To date, few publications have compared the overall survival of patients with locoregional and metastatic BC and correlated it with the patients' baseline characteristics. A study conducted in patients diagnosed with BC in 1990-1999 in 10 European countries identified 5- and 10-year all-cause overall survival rates of $89 \%$ and $80 \%$, respectively (13). An analysis conducted in the Cote D'Or registry on patients with metastatic BC diagnosed in 2000-2011 showed survival rates at 1 and 2 years of $67.3 \%$ and $47.5 \%$, respectively, with a median survival of 22.7 months (16). Another publication on this topic reported overall survival of $92.9 \%, 77.6 \%$ and $65.5 \%$ at 1,3 and 5 years, respectively, in Italian women diagnosed in 1979-1981 (24). A further study conducted on Scottish women with non-metastatic BC diagnosed in 19871993 showed that the 8-year overall survival decreased with age (12), and another analysis of Turkish women conducted between 1995 and 2008 found a median survival of 120 months, with $90 \%$ survival at the 5-year cut-off date (22). Additionally, a retrospective study conducted on patients with metastatic BC diagnosed in 1980-2009 in Germany reported a median survival of 85 months, with worse survival outcomes for patients diagnosed more recently (31).

In the period 2000-2007, the overall cumulative survival for Portuguese patients with BC was $94.68 \%, 85.17 \%$ and $77.42 \%$, at 1, 3 and 5 years, respectively (26). The age at diagnosis and year of diagnosis have been associated with different overall survival rates in patients in South Portugal diagnosed with $\mathrm{BC}$ (4-9, 15, 23). Furthermore, an imbalance in BC overall survival in the different regions of the South Regional Cancer Registry (ROR-Sul) was reported in 2000-2001 (4). However, it did not reach a statistical significance in the 2005 study conducted on this population (23). This later analysis also described a 5-year 
overall survival rate of $80 \%$, with lower survival being reported in patients with higher stages of BC at diagnosis $(92 \%, 86 \%$, $60 \%$ and $20 \%$ for stages I-IV, respectively) (23).

Considering the lack of epidemiological data on overall survival among patients with locoregional and metastatic BC according to their baseline characteristics and its potential implications for healthcare policy making (10), this study aimed to characterize the overall survival among patients with BC diagnosed between 2005 and 2012 in South Portugal, considering several demographic, clinical and contextual characteristics, globally and by sub-groups (locoregional and metastatic).

\section{Materials and Methods}

Data and sources. A retrospective observational clinical cohort study was carried out. New female cases with malignant BC (C50) (32) registered in the ROR-Sul registry (South of Portugal and Madeira) between 2005 and 2012 were included. The file containing the database record for the incident $\mathrm{BC}$ cases was registered in the National Commission for Data Protection as of December 1997 (no. 1973500003). For this specific study, Ethics Committee approval and informed consent were not required since the data were based on an official national surveillance system and had been previously anonymized. Six counties out of the 126 covered by ROR-Sul were not included in this study because they only started reporting cancer cases to this registry in 2009 .

Methods. The survival of incident cases of BC was analyzed globally and stratified by locoregional and metastatic disease at diagnosis because this allows a better understanding of temporal changes in survival (18) and associated factors. Patients with unknown stage at diagnosis were excluded from this analysis. The Kaplan-Meier method was used for the estimation of all-cause survival, considering the date of BC diagnosis and date of death/last follow-up. The Kaplan-Meier estimate represents the probability of a patient surviving after a certain period of follow-up (33). This method determines the survival in time intervals not defined a priori but depending on the occurrence of the event of interest (death) (19). The statistical significance between different Kaplan-Meier curves was analyzed using the log-rank Mantel-Cox test, allowing comparison of survival curves between groups $(33,34)$. These methods are commonly used in clinical trials $(33,34)$ and consider the individual follow-up periods $(18,33,34)$, therefore being the most accurate measure of disease prognosis (18). Multivariate Cox regression models were applied to model global survival and that of both groups (locoregional and metastatic), with the obtained coefficients interpreted as hazard ratios [(HR), crude or adjusted] $(33,34)$.

Patients were divided into four age groups: $<40,40-49,50-64$ and $\geq 65$ years $(12,14,16,23,30,35)$. The median population density in the analyzed period was calculated for each county, and the cut-off value of 300 inhabitants $/ \mathrm{km}^{2}$ was applied for the definition of urban/non-urban areas (36). Morphology and topography were coded according to International Classification of Diseases for Oncology (ICD-O) version 3 (32). The different morphologies were grouped as papillary (M8050/3,M8503/3), mucinous (M8480/3, M8481/3, M8482/3), ductal (M8500/3), lobular (M8520/3) and ductal-lobular $(\mathrm{M} 8522 / 3)(23,32,37)$, while the remaining codes were grouped in the category "Other" [due to the low incidence of each individual morphology $(<1 \%)]$. The data were analyzed using the Statistical Package for Social Sciences (SPSS ${ }^{\mathrm{TM}}$, version 22 for Windows; IBM, Armonk, NY, USA), and the significance level was set at 0.05 .

\section{Results}

In this study, 19,597 out of the 23,202 women diagnosed with malignant BC (C50) from 2005 to 2012 in the Southern region of Portugal and Madeira were included; 3,599 (15.5\%) patients were excluded due to unknown stage at diagnosis, six had no or incorrect record of follow-up time. Most women were Portuguese $(96.4 \%)$ and presented locoregional $(n=18,190 ; 78.4 \%)$ or metastatic disease $(n=1,413 ; 6.1 \%)$ at diagnosis. The mean \pm standard deviation age at diagnosis was $60.35 \pm 14.26$ years (median $=60$ years, range $=15-102$ years). At the cut-off date (31 March 2017), the median follow-up period since diagnosis was 49 (range $=0$-143) months, being longer in patients with locoregional than in those with metastatic disease [51 (range $=0-143$ ) and 27 (range=0-139) months, respectively]. The 1-, 3-, 5- and 10-year survival was higher in the locoregional $(96.8 \%, 89 \%, 80.5 \%$ and $44.1 \%)$ than in the metastatic subgroup $(70.4 \%, 42.9 \%, 28.1 \%$ and $11.2 \%)$. Details on the demographic characteristics, median survival (from time of diagnosis, stratified into locoregional and metastatic at diagnosis) and cumulative survival of patients with $\mathrm{BC}$ can be found in Table I. Additionally, an analysis including the 23,202 women with $\mathrm{BC}$ from the registry found no major differences in the results obtained in this analysis [1-, 3, 5 and 10-year survival: $94.2 \%, 84.8 \%, 75.8 \%$ and $40.0 \%$; median survival $=112$ months, $95 \%$ confidence interval $(\mathrm{CI})=110.15$ 113.85 months] (data not shown).

An association between median survival and stage at diagnosis was identified in these patients, being significantly superior in the locoregional subgroup (115 vs. 31 months in patients with metastasis, $p<0.001)$. The year of diagnosis, age at diagnosis, district of residence, topography and morphology of the tumor were also significantly associated with the survival of patients with BC $(p<0.001)$, even after being stratified into two stages at diagnosis (see below). In patients with metastatic $\mathrm{BC}$, median survival was higher in the urban context ( $p=0.009)$ (data not shown).

Patients with metastatic stage at BC diagnosis had an almost 6-fold higher risk of death than those with locoregional $\mathrm{BC}$, and women diagnosed at 65 years of age or older had an almost three times higher risk of death than those under 40 years of age at diagnosis. Conversely, patients diagnosed at the ages of 40-49 years had an 18\% lower risk of death than women diagnosed at younger ages. Patients living in Faro, Madeira and Santarém had a significantly higher risk of death than those living in Lisbon (HRs of 1.15, 1.27 and 1.08, respectively), and patients with $\mathrm{BC}$ topographies $\mathrm{C} 50.1-5$ and C50.8 had a lower risk of death than those with C50.9 tumors $(\mathrm{HR}=0.65-0.84)$. The risk of death among patients with $\mathrm{BC}$ 
Table I. Demographic characteristics, and cumulative and median survival of patients with locoregional and metastatic breast cancer diagnosed in South Portugal and Madeira between 2005 and $2012(n=19,597)$.

\begin{tabular}{|c|c|c|c|c|c|c|c|c|}
\hline & \multirow{2}{*}{$\begin{array}{l}\mathrm{N} \text { (Locoregional/ } \\
\text { metastatic) }\end{array}$} & \multicolumn{4}{|c|}{ Cumulative survival (\%) } & \multicolumn{3}{|c|}{ Median survival $(95 \% \mathrm{CI})$, months } \\
\hline & & 1-Year & 3-Year & 5-Year & 10-Year* & Overall & Locoregional & Metastatic \\
\hline All patients & $19,597(18,190 / 1,413)$ & 94.9 & 85.6 & 76.5 & 41.5 & $112.00(109.82-114.18)$ & $115.00(112.68-117.32)$ & $31.00(29.03-32.97)$ \\
\hline \multicolumn{9}{|c|}{ Year of diagnosis } \\
\hline 2005 & $1,941(1,732 / 210)$ & 93.7 & 85.1 & 77.7 & 49.1 & $120.00(117.45-122.52)$ & $122.00(119.47-124.53)$ & $41.00(31.00-51.00)$ \\
\hline 2006 & $1,989(1,822 / 167)$ & 94.4 & 85.1 & 78 & 38.0 & $111.00(108.59-113.41)$ & $112.00(109.48-114.52)$ & $33.00(22.56-43.44)$ \\
\hline 2007 & $2.047(1,906 / 141)$ & 94 & 84.6 & 77 & 36.1 & $100.00(96.26-103.74)$ & $103.00(99.39-106.61)$ & $26.00(18.24-33.76)$ \\
\hline 2008 & $2,448(2,273 / 175)$ & 94.9 & 86.5 & 79.9 & 32.1 & $88.00(85.33-90.67)$ & $90.00(86.57-93.44)$ & $34.00(26.26-41.74)$ \\
\hline 2009 & $2,659(2,486 / 173)$ & 94.8 & 86.7 & 78.1 & 32.6 & $79.00(74.98-83.02)$ & $84.00(78.76-89.24)$ & $24.00(15.87-32.13)$ \\
\hline 2010 & $2,750(2,584 / 166)$ & 95.1 & 86.1 & 66 & 35.2 & $73.00(68.99-77.01)$ & $76.00(72.16-79.84)$ & $30.00(24.01-35.99)$ \\
\hline 2011 & $2,859(2,662 / 193)$ & 95.4 & 85.2 & 58.3 & 31.2 & $66.00(66.52-71.48)$ & $70.00(66.64-73.36)$ & $28.00(24.21-31.79)$ \\
\hline 2012 & $2,904(2,716 / 188)$ & 95.9 & 80.9 & 40.6 & NR & $59.00(53.15-64.86)$ & $59.00(55.10-62.90)$ & $28.00(24.33-31.67)$ \\
\hline \multicolumn{9}{|c|}{$\begin{array}{l}\text { Age at diagnosis } \\
\text { (years) }\end{array}$} \\
\hline$<40$ & $1,401(1,330 / 71)$ & 98 & 92.6 & 85.4 & 48.9 & $118.00(110.10-125.91)$ & 130.00 & $40.00(26.92-53.09)$ \\
\hline $40-50$ & $3,611(3,404 / 207)$ & 98.1 & 93.2 & 87.5 & 61.4 & $129.00(119.08-138.92)$ & $129.00(118$ & $47.00(34.91-59.09)$ \\
\hline $50-64$ & $6,767(6,301 / 465)$ & 96.9 & 90.5 & 83.7 & 56.7 & $124.00(117.76-130.24)$ & $129.00(123.75-134.25)$ & $36.00(31.59-40.41)$ \\
\hline$\geq 65$ & $7,818(7,148 / 650)$ & 91.1 & 76.8 & 63.9 & 22.4 & $87.00(83.99-90.01)$ & $94.00(90.85-97.15)$ & $24.00(21.02-26.98)$ \\
\hline \multicolumn{9}{|c|}{ District of residence } \\
\hline Lisbon & $9,901(9,083 / 818)$ & 95.2 & 86.1 & 76.9 & 43.4 & $114.00(110$ & 117.00 & $33.00(29$ \\
\hline Beja & $510(472 / 38)$ & 93.3 & 86.1 & 79.9 & 33.0 & $112.00(100.35-123.65)$ & $118.00(100.22-135.78)$ & $13.00(0.00-31.86)$ \\
\hline Évora & $606(550 / 56)$ & 94.4 & 84.0 & 78.1 & 37.2 & $119.00(113.47-124.53)$ & $120.00(113.52-126.48)$ & $28.00(22.01-33.99)$ \\
\hline Faro & $1,921(1,781 / 140)$ & 94 & 83.6 & 74.5 & 36.9 & $110.00(103.81-116.19)$ & $112.00(106.36-117.64)$ & $30.00(25.13-34.87)$ \\
\hline Madeira & $1,021(971 / 50)$ & 93.6 & 83.1 & 71.1 & 29.5 & $104.00(97.37-110.63)$ & $104.00(99.61-108.39)$ & $16.00(10.40-21.61)$ \\
\hline Portalegre & $332(287 / 45)$ & 93.4 & 83.0 & 74.8 & 47.6 & $104.00(96.55-222.45)$ & $132.00(\mathrm{NC})$ & $29.00(21.38-36.62)$ \\
\hline Santarém & $1,912(1,799 / 113)$ & 94.8 & 84.8 & 75.7 & 40.0 & $111.00(105.93-116.07)$ & $114.00(109.15-118.85)$ & $25.00(20.58-29.42)$ \\
\hline Setúbal & $3,394(3,241 / 153)$ & 95.2 & 87 & 78.2 & 40.7 & $112.00(106.66-117.34)$ & $113.00(107.02-118.98)$ & $42.00(34.18-49.82)$ \\
\hline \multicolumn{9}{|c|}{ (1) } \\
\hline C50.0 & $51(48 / 3)$ & 88.2 & 77.8 & 67.1 & 5 & $\mathrm{NC}$ & & $3.60)$ \\
\hline $\mathrm{C} 50.1$ & $673(634 / 39)$ & 95.7 & 87.2 & 79.1 & & $0(98.44$ & 100.58 & $6-43.34)$ \\
\hline $\mathrm{C} 50.2$ & 1,3 & 96.5 & 88.7 & 81.6 & 29.1 & $112.00(108.5$ & $114.00(109.3$ & $7-42.93)$ \\
\hline C50.3 & $801(762 / 39)$ & 97.1 & 90.6 & 80.1 & 42.2 & $114.00(105.38-122.62)$ & $114.00(107.25-120.75)$ & $34.00(21.54-46.46)$ \\
\hline C50.4 & $4,860(4,644 / 216)$ & 96.7 & 89 & 81.2 & 50.7 & $121.00(115.55-126.45)$ & $122.00(118.02-125.98)$ & $34.00(28.07-39.93)$ \\
\hline $\mathrm{C} 50.5$ & $908(855 / 53)$ & 97.5 & 89.8 & 80.7 & 36.1 & $114.00(107.49-120.51)$ & $114.00(104.81-123.19)$ & $33.00(17.35-48.65)$ \\
\hline C50.6 & $43(37 / 6)$ & 86.0 & 76.5 & 73.5 & 63.8 & $\mathrm{NC}$ & $\mathrm{NC}$ & $40.00(0.00-100.76)$ \\
\hline C50.8 & $2,984(2,801 / 183)$ & 96.1 & 86.3 & 75.6 & 42.4 & $111.00(106.67-115.33)$ & $115.00(107.40-122.60)$ & $32.00(25.06-38.94)$ \\
\hline C50.9 & $7,921(7,108 / 813)$ & 92.5 & 81.8 & 72.2 & 36.7 & $108.00(105.24-110.76)$ & $112.00(108.91-115.09)$ & $29.00(25.72-32.28)$ \\
\hline \multicolumn{9}{|l|}{ Morphology } \\
\hline Ductal & $14,660(13,824 / 836)$ & 95.9 & 87 & 7 & 43.8 & $114.00(111.14-116.86)$ & $118.00(115.16-120.85)$ & $33.00(29.83-35.17)$ \\
\hline Papillary & $206(201 / 5)$ & 97.1 & 84.9 & 79.6 & & $\mathrm{NC}$ & $\mathrm{NC}$ & $67.00(34.07-99.93)$ \\
\hline Mucinous & $277(263 / 14)$ & & 87.7 & 74.6 & & $102.00(88.87-115.13)$ & $102.00(90.01$ & $65.00(28.00-102.00)$ \\
\hline Lobular & $991(910 / 81)$ & & 86.7 & 76.5 & 35.8 & $110.00(104.36-115.64)$ & $111.00(106.78-115.22)$ & $32.00(27.38-36.62)$ \\
\hline DL & $315(308 / 7)$ & 97.7 & 92.4 & 84.9 & 25.9 & $112.00(105.11-118.89)$ & $112.00(105.13-118.88)$ & $69.00(33.24-104.76)$ \\
\hline Other & $3,148(2,678 / 470)$ & 89.7 & 77.9 & 69.1 & 36.5 & $105.00(100.16-109.84)$ & $112.00(105.70-118.30)$ & $21.00(16.16-25.84)$ \\
\hline \multicolumn{9}{|l|}{ Urbanicity } \\
\hline Urban & $6,963(6,475 / 489)$ & 95 & 86.1 & 76.9 & 42.3 & $112.00(109.19-114.81)$ & $114.00(110.70-117.30)$ & $27.00(23.89-30.11)$ \\
\hline Non-urban & $12,633(11,709 / 924)$ & 94.6 & 84.8 & 76 & 40.3 & $112.00(109.06-114.94)$ & $117.00(113.69-120.31)$ & $33.00(30.00-36.00)$ \\
\hline
\end{tabular}

NC: Not computed; DL: ductal-lobular; CI: confidence interval; NR: not reached. *Only patients diagnosed before 2008 were considered in this analysis, as the median follow-up period was below 120 months for patients diagnosed after 2008. \#According to (32): C50.0: Nipple; C50.1: central portion of breast; C50.2: upper-inner quadrant of breast; C50.3: lower-inner quadrant of breast; C50.4: upper-outer quadrant of breast; C50.5: lowerouter quadrant of breast; C50.6: axillary tail of breast; C50.8: overlapping lesion of breast; C50.9: breast, not otherwise specified.

increased by $8.8 \%$ per year in the analyzed period and patients with "Other" morphologies had a risk of death 1.51 times greater than patients with ductal histology, in contrast with an HR reduction of $23 \%$ for those with ductal-lobular tumors.
Patients with metastatic BC aged 40-49 years at diagnosis had a significantly lower risk of death when compared with younger patients than did their counterparts with locoregional disease (HR=0.69 vs. 0.81, respectively). On the other hand, 
patients with locoregional disease diagnosed at 65 years of age or higher had a higher risk of death compared with patients under 40 years old than those with metastatic disease at diagnosis (HR: 3.10 vs. 1.37). Patients with locoregional BC living in Faro, Madeira, Santarém and Setúbal presented a higher risk of death than those living in the Lisbon region, whereas only patients with metastatic BC in Madeira had an increased risk of death when compared with patients from Lisbon. The locoregional tumor topographies C50.2-5 were associated with a lower risk of death than those with locoregional C50.9 tumors. Additionally, patients with metastatic BC with C50.0 topographies had a higher risk of death $(\mathrm{HR}=5.91)$, whereas those with locations C50.2, C50.4 and C50.5 presented HRs of $0.59-0.78$ versus those with C50.9 tumors. Both patients with locoregional and metastatic BC had a higher risk of death when presenting "Other" histologies than tumors of ductal histology (1.22- and 1.39fold, respectively). Finally, patients with metastatic disease at diagnosis presented a 1.18-fold increased risk of death when living in non-urban areas when comparing with those from urban centers.

After adjustment for the demographic, clinical and contextual characteristics, the stage at diagnosis, year of diagnosis, age at diagnosis, district of residence, topography and morphology of the tumor were significantly associated with the survival of patients overall, and those with locoregional and metastatic BC $(p<0.001$, Table II and Figure 1).

\section{Discussion}

This study was the first long-term overall survival analysis of female patients with BC in the South of Portugal, contributing as a starting point for future studies on this area. The overall cumulative survival at $1,3,5$ and 10 years $(94.9 \%, 85.6 \%$, $76.5 \%$ and $41.5 \%$, respectively) did not diverge from the previously reported outcomes for this population [1 year: 93 96\%, 3 years: $8287 \%, 5$ years: $75-80 \%(4-9,15,23)]$. These cumulative survival rates were slightly higher than those reported in Italian women in the period 1979-1981 (24), but were inferior to the 5- and 10-year cumulative survival reported for European women in the period 1990-1999 (13). These variances might be attributed to differences in the population analyzed (age or stage at diagnosis, histological subtype), the presence and imbalance of competing causes of death, divergences in the registry methods or therapeutic approaches (17) in the different countries or the evolution of therapeutic options over time.

Patients with locoregional BC exhibited better median survival and cumulative survival rates than those with metastatic disease at diagnosis, agreeing with previously published data correlating stage at diagnosis with survival (10$14,17,20-23)$. In patients with metastatic disease, the cumulative survival rate at 1 and 2 years $(70.4 \%$ and $57.8 \%)$ further matched the $67.3 \%$ and $47.5 \%$ reported for the French registry study (16) but the median overall survival (31 months) was quite inferior to that reported in a German study (85 months) (31). These divergences can point to management differences in these countries or a delay in the uptake of new available therapeutic approaches to more complex cases in some regions.

The 1- and 3-year cumulative survival rate showed stabilization in the studied period $(93.7 \%$ to $95.9 \%$ and $85.1 \%$ to $80.9 \%$, respectively), differing only slightly from previously published data on this population $(94-96 \%$ and $84-87 \%$, respectively) (6-9). On the other hand, the 5-year cumulative survival rate decreased over the studied period (from $77.7 \%$ to $40.6 \%$ ), contradicting published data for developed countries (10-16). Additionally, a more recent year of diagnosis was associated with a higher risk of death (HRs of 1.10, 1.12 and 1.08 for patients overall, those with locoregional and those with metastatic disease, respectively). This trend may potentially be attributed to the fact that the survival curves might not be accurate for the latter years of the analyzed period.

Women diagnosed with $\mathrm{BC}$ at $<40$ years presented a lower survival than those diagnosed at the ages of 40-49 years (median survival: 118 vs. 129 months, $\mathrm{HR}=0.82, p=0.015$ ). These results match the published data on BC Portuguese women $(4-9,15,26)$ suggesting that younger patients might present a more aggressive BC phenotype (22). Patients diagnosed at 65 years and older had a significantly inferior median survival compared to the younger groups ( 87 months) and had a risk of death of almost threefold higher than that of patients under 40 years at diagnosis, with differences in survival being detected early in the follow-up period. As BC diagnosis in older women has been associated with reduced use of more aggressive therapeutic options (10) and they show increased mortality from other causes (20), these results are within the expected range for this group $(4-9,12,15,26)$.

When considering patients with locoregional $\mathrm{BC}$, the younger age groups had a longer median survival than patients aged 65 years or more $(\mathrm{HR}=3.10)$, agreeing with previously reported data for non-metastatic BC (12). In the group with metastatic BC, patients aged 40-49 years at diagnosis had the longest median survival, contrasting with the older group (24 months, $\mathrm{HR}=1.37$ ), results that can potentially be attributed to the presence of comorbidities (17) and reduced investment in the therapy of elderly women (10).

Patients living in Faro, Madeira, and Santarém had an increased risk of death when compared to those living in the capital (HRs of 1.15, 1.27 and 1.08, respectively). This uneven distribution of survival was previously reported by others (4, 23). Despite the fact that the patients from the non-continental area (Madeira) had a lower cumulative survival versus those living in Lisbon, some improvement in the survival rates was observed from previous publications [1-, 3- and 5-year 


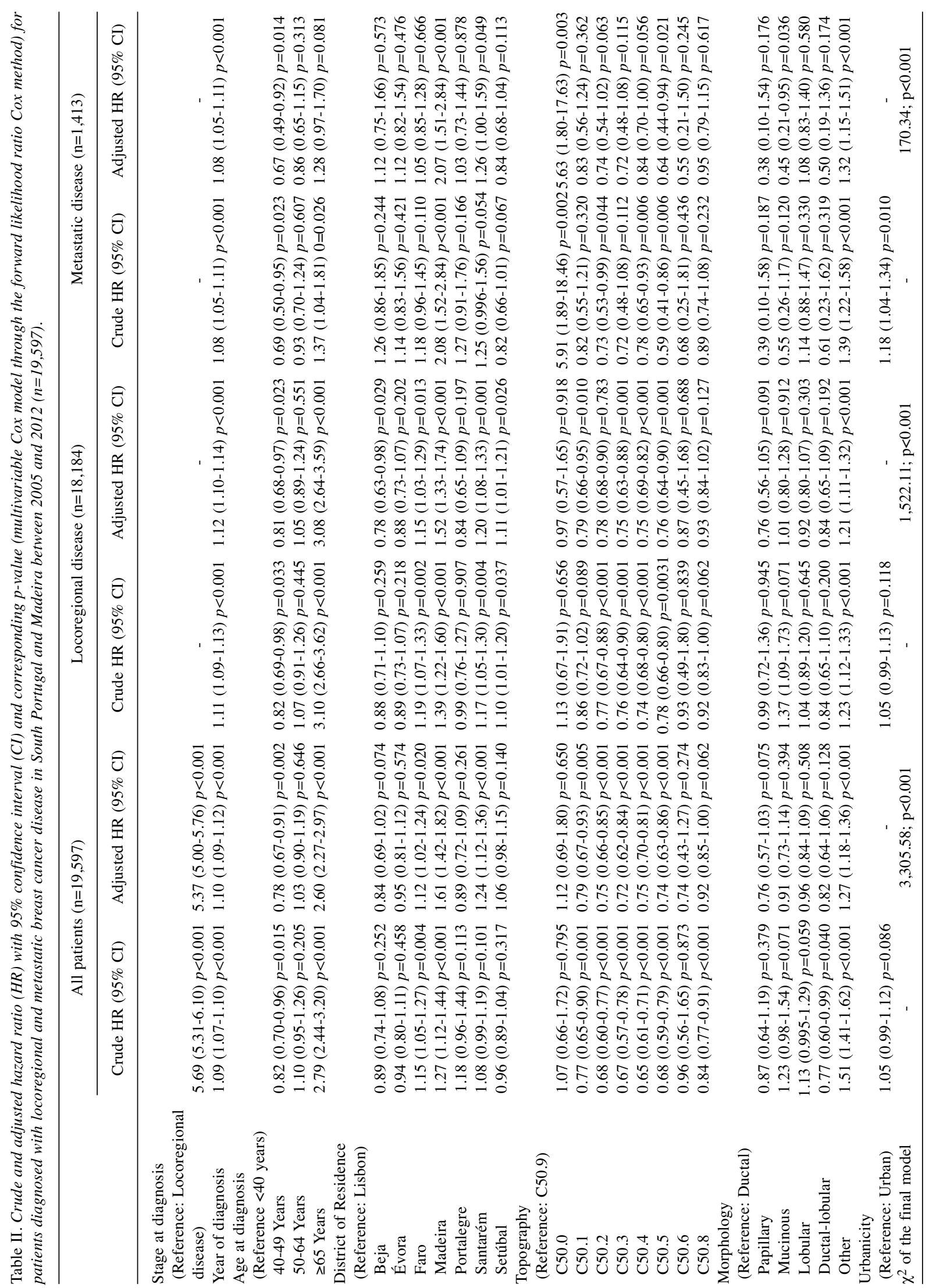




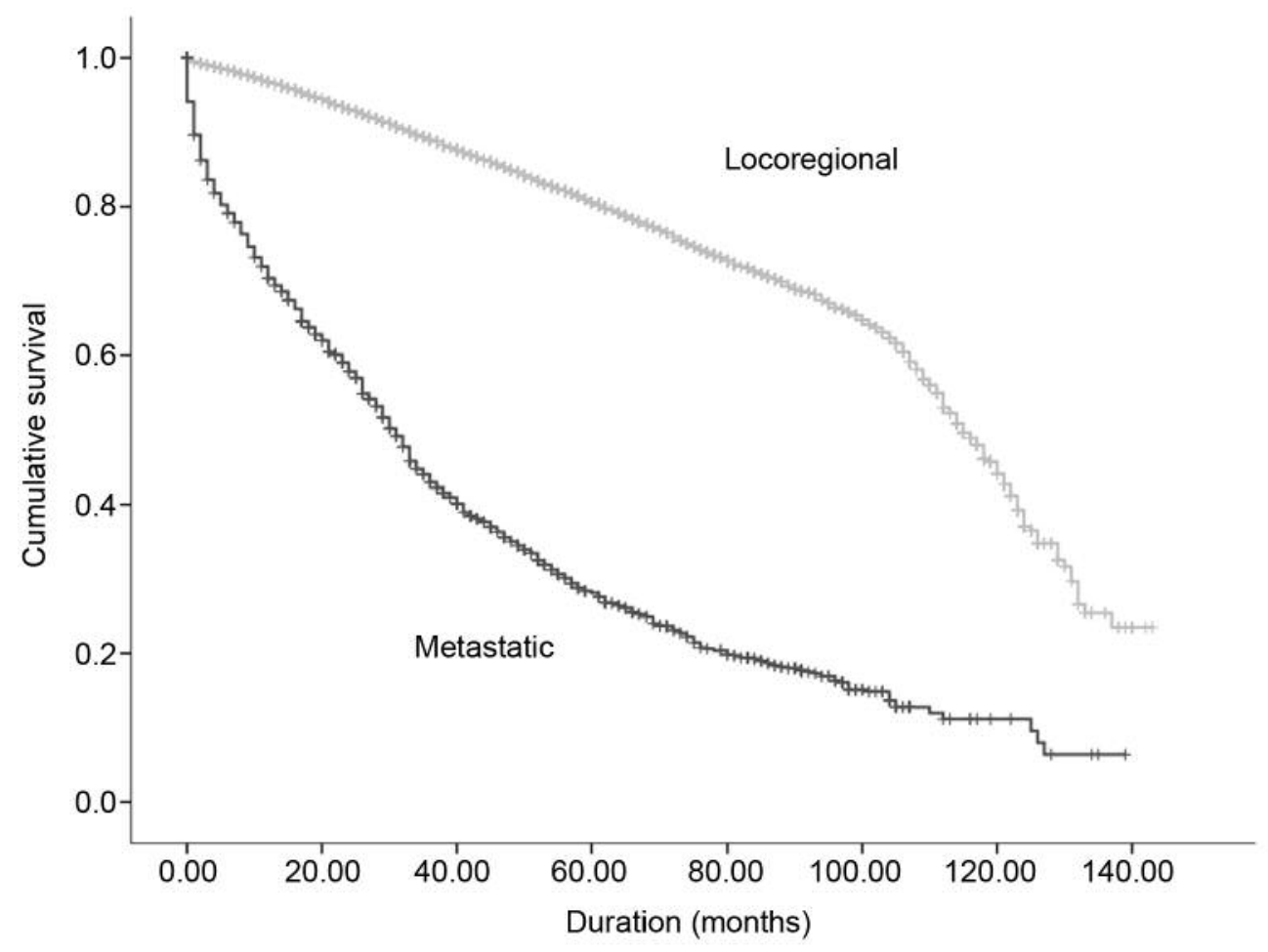

Figure 1. Kaplan-Meier curves for the adjusted final model for patients with locoregional and metastatic breast cancer (log-rank $p<0.001)$.

survival of $92 \%$ (4) vs. $93.6 \%, 76 \%$ (4) vs. $83.1 \%$, and $66 \%$ (4) vs. $71.1 \%$, respectively], suggesting a reduction in inequities in healthcare. This asymmetrical distribution of survival was also reflected in the analysis conducted on those with locoregional and metastatic BC, for whom living in Madeira was associated with the highest risk of death (HRs of 1.39 and 2.08, respectively).

When comparing the death risk by topography, most tumor locations (except C50.6) were associated with a lower risk of death than C50.9 (HR=0.65-0.84). The association between tumor location and survival had been reported previously (30). However, the median survivals described in the publication by Rummel et al. (30) and the current study were utterly different (C50.1: 108 vs. 21 months, C50.2: 112 vs. 68 months, C50.3: 114 vs. 72 months, C50.4: 121 vs. 18 months, and C50.5: 114 vs. 37 months), which might be a reflection of local practice or registry variances. Although patients overall and the locoregional subgroup presenting C50.4 tumors had better median survival outcomes (121 vs. 108-114 months and 122 $v s$. 111-115 months, respectively), those with metastatic BC had similar median survival durations across the different tumor locations. Statistically significant differences were also reported in the Cox analysis of locoregional and metastatic BC between the C50.9 tumors and C50.2-5, and C50.2, C50.4 and C50.5, respectively, pointing to a differential correlation between the risk of death and tumor location in these subgroups of patients.

In this study, patients with $\mathrm{BC}$ presenting ductal, ductallobular and lobular tumors had a longer median survival than those with other histologies (114, 112 and 110 months, respectively), with those with lobular and ductal tumors presenting similar results to previously described survival rates $(13,16,29)$. The survival curve for patients with ductallobular BC showed significantly different progression from that of ductal tumors $(-30.4 \%$ risk of death) that then eventually reversed at the 10-year analysis (25.9\% vs. $43.8 \%$ cumulative survival). This inversion may potentially be explained by the positive selection (better prognosis) of patients with ductal $\mathrm{BC}$ or immaturity of the data for the analysis at the 10-year follow-up. On the other hand, patients with 'Other' histologies had a 1.5 times higher risk of death than patients with ductal tumors, being aligned with data on survival among different histological BC types $(16,28)$. Additionally, the 5-year cumulative survival of patients with ductal and lobular tumors were similar to those reported by other authors ( $78 \%$ vs. $82 \%$ and $76.5 \%$ vs. $81 \%$, respectively) (29). When considering locoregional and metastatic BC, the survival according to histology presented some divergences, with patients with ductal and ductal-lobular (118 and 69 months, respectively) exhibiting the longest median survival, 
and mucinous and 'Other' histologies being associated with lower median survival (102 and 21 months, respectively). Furthermore, patients with 'Other' histologies differed significantly from those with ductal tumors in the risk of death in both locoregional and metastatic BC (HR of 1.23 and 1.39, respectively), pointing to a correlation between the histological subtype and survival in patients with BC.

No differences were reported in the median survival of patients living in rural and urban areas, confirming the findings of other studies $(24,35)$. However, in the subgroup analysis of those with metastatic $\mathrm{BC}$, a significant difference was reported in the median survival of patients living in rural and urban settings (27 vs. 33 months; $H R=1.18$ ), which may potentially be explained by different access to more cuttingedge therapeutics in more challenging BC cases.

The methodological choice of studying overall survival might bias the results of this study, as competing causes of death (17) bear weight particularly in older patients (20) hereby affecting their long-term overall survival (19). The overall survival rate was selected over relative survival because it is of utmost relevance for proper planning of health resources (10), especially in long-term survival of patients with cancer. The results of this analysis should, however, be considered with some caution, as data on the clinical evolution of patients after diagnosis, the presence of comorbidities or prognostic factors such as the presence of estrogen/progesterone receptors and the treatment sequences per patient were not evaluated. Finally, a high percentage of patients with unknown stage at diagnosis $(15.5 \%)$ were excluded from this analysis. This fact, together with a potential lower accuracy of the database in the latter years analyzed, might account for some of the divergences in these survival results from previously published data.

Overall, this study identified distinct survival patterns for patients with locoregional and metastatic BC at diagnosis, highlighting the importance of earlier diagnosis. Furthermore, this was the first analysis looking into the impact of demographic, clinical and contextual characteristics on $\mathrm{BC}$ survival in locoregional and metastatic BC over time, providing a background for potential future studies on this topic. Additional analysis on survival and its connection to incidence and mortality would be beneficial for the understanding of this cancer type in the Portuguese community.

\section{Conflicts of Interest}

There were no sources of funding or conflict of interests to declare in regard to this study.

\section{Authors' Contributions}

IG was responsible for conception and design of this study, analysis and interpretation of data; drafting the article and revising. PA was responsible for the conception and design of this study, as well as interpretation/discussion of the results. AM was responsible for the interpretation/discussion of the results. $\mathrm{CN}$ was also responsible for conception and design of this study, acquisition of data and interpretation/discussion of the results. All Authors read and approved the final version to be published.

\section{Acknowledgements}

The Authors thank the South Regional Cancer Registry for kindly providing the data for this study.

\section{References}

1 Torre LA, Bray F, Siegel RL, Ferlay J, Lortet-Tieulent J and Jemal A: Global Cancer Statistics, 2012. CA Cancer J Clin 65: 87-108, 2015. PMID: 25651787. DOI: 10.3322/caac. 21262

2 Ferlay J, Soerjomataram I, Dikshit R, Eser S, Mathers C, Rebelo M, Parkin DM, Forman D and Bray F: Cancer incidence and mortality worldwide: Sources, methods and major patterns in GLOBOCAN 2012. Int J Cancer 136: E359-386, 2015. PMID: 25220842. DOI: $10.1002 / \mathrm{ijc} .29210$

3 Ferlay J, Steliarova-Foucher E, Lortet-Tieulent J, Rosso S, Coebergh JWW, Comber H, Forman D and Bray F: Cancer incidence and mortality patterns in Europe: Estimates for 40 countries in 2012. Eur J Cancer 49: 1374-1403, 2013. PMID: 23485231. DOI: 10.1016/j.ejca.2012.12.027

4 Registo Oncológico Regional Sul I-E: Top 10 Os 10 tumores mais frequentes na população portuguesa adulta na região sul de Portugal, no período 2000|2001, 2008.

5 Registo Oncológico Regional Sul: ISM - $2002 / 2003$ Incidência, Sobrevivência e Mortalidade do Cancro na Região Sul de Portugal. Registo Oncológico Regional Sul Instituto Português de Oncologia de Lisboa Francisco Gentil EPE (ed.). Lisboa, 2010.

6 Registo Oncológico Regional Sul: ISM 2004|2005- Incidência, Sobrevivência e Mortalidade do Cancro na Região Sul de Portugal. Registo Oncológico Regional Sul Instituto Português de Oncologia de Lisboa Francisco Gentil EPE (ed.). Lisboa, 2010.

7 Registo Oncológico Regional Sul: ISM 2007 - Incidência, Sobrevivência e Mortalidade de todos os tumores na população residente na região sul de Portugal, em 2007. Registo Oncológico Regional Sul Instituto Português de Oncologia de Lisboa Francisco Gentil EPE (ed.). Lisboa, 2013.

8 Registo Oncológico Regional Sul: ISM 200812009 - Incidência, Sobrevivência e Mortalidade de todos os tumores na população residente na região sul de Portugal, em 200812009. Registo Oncológico Regional Sul Instituto Português de Oncologia de Lisboa Francisco Gentil EPE (ed.). Lisboa, 2014.

9 Registo Oncológico Regional Sul: ISM 2010|2011- Incidência, Sobrevivência e Mortalidade do Cancro na Região Sul de Portugal. Registo Oncológico Regional Sul Instituto Português de Oncologia de Lisboa Francisco Gentil EPE (ed.). Lisboa, 2017.

10 Coleman MP, Forman D, Bryant H, Butler J, Rachet B, Maringe C, Nur U, Tracey E, Coory M, Hatcher J, McGahan CE, Turner D, Marrett L, Gjerstorff ML, Johannesen TB, Adolfsson J, Lambe M, Lawrence G, Meechan D, Morris EJ, Middleton R, Steward J and Richards MA: Cancer survival in Australia, Canada, Denmark, Norway, Sweden, and the UK, 1995-2007 (the International Cancer Benchmarking Partnership): An analysis of population-based cancer registry data. Lancet 377: 127-38, 2011. PMID: 21183212. DOI: 10.1016/S0140-6736(10) 62231-3 
11 Webb PM, Cummings MC, Bain CJ and Furnival CM: Changes in survival after breast cancer: Improvements in diagnosis or treatment? The Breast 13: 7-14, 2004. PMID: 14759710. DOI: 10.1016/S0960-9776(03)00129-2

12 Thomson CS, Brewster DH, Dewar JA and Twelves CJ: Improvements in survival for women with breast cancer in Scotland between 1987 and 1993: impact of earlier diagnosis and changes in treatment. Eur J Cancer 40: 743-753, 2004. PMID: 15010076. DOI: 10.1016/j.ejca.2003.08.02

13 Blamey RW, Hornmark-Stenstam B, Ball G, Blichert-Toft M, Cataliotti L, Fourquet A, Gee J, Holli K, Jakesz R, Kerin M, Mansel R, Nicholson R, Pienkowski T, Pinder S, Sundquist M, Vijver M van de and Ellis I: ONCOPOOL - A European database for 16,944 cases of breast cancer. Eur J Cancer 46: 56-71, 2010 PMID: 19811907. DOI: 10.1016/j.ejca.2009.09.009

14 Barchielli A and Paci E: Trends in breast cancer mortality, incidence, and survival, and mammographic screening in Tuscany, Italy. Cancer Causes Control 12: 249-255, 2001. PMID: 11405330. DOI: 10.1023/A:1011280204842

15 International Agency for Research on Cancer - World Health Organization: Survival Curves - Portugal, South. EUREG, 2012. Available from: http://eco.iarc.fr/EUREG/AnalysisG.aspx (last accessed February 6, 2018)

16 Marshall EM, Bertaut A elie, Desmoulins I, Darut-Jouve A, Ponnelle T, Poillot M-L, Beltjens F and Arveux P: Prognostic Factors of Survival among Women with Metastatic breast cancer and impact of primary or secondary nature of disease on survival: A French population-based study. Breast J: 23: 138-45, 2017. PMID: 27935232. DOI: $10.1111 /$ tbj. 12717

17 Autier P and Boniol M: Caution needed for country-specific cancer survival. Lancet 377: 99-101, 2011. PMID: 21215872. DOI: $10.1016 / \mathrm{S} 0140-6736(10) 62347-1$

18 Ellis L, Woods LM, Estève J, Eloranta S, Coleman MP and Rachet B: Cancer incidence, survival and mortality: Explaining the concepts. Int J Cancer 135: 1774-1782, 2014. PMID: 24945976. DOI: $10.1002 / \mathrm{ijc} .28990$

19 International Agency for Research on Cancer: Descriptive Epidemiology. In: Statistical Methods in Cancer Research. Esteve J, Benhamou E and Raymond L (eds.). Lyon, World Health Organization, 1994.

20 Sant M, Francisci S, Capocaccia R, Verdecchia A, Allemani C and Berrino F: Should we use incidence, survival or mortality to assess breast cancer trends in European women? Nat Clin Pract 3: 228-229, 2006. PMID: 16682983. DOI: 10.1038/ncponc0489

21 Karjalainen S, Aareleid T, Hakulinen T, Pukkala E, Rahu M and Tekkel M: Survival of female breast cancer patients in Finland and in Estonia: Stage at diagnosis important determinant of the difference between countries. Sot Sci Med 28: 233-238, 1989. PMID: 2919310. DOI: 10.1016/0277-9536(89)90266-

22 Gokce T, Karadogan I and Akçay C: A long-term survival pattern for breast cancer treated in a single institution. Indian $\mathrm{J}$ Cancer 48: 187-193, 2011. PMID: 21768664. DOI: 10.4103/ 0019-509X.82884

23 André M do R, Amaral S, Mayer A and Miranda A: Breast cancer patients survival and associated factors: Reported outcomes from the Southern Cancer Registry in Portugal. Acta Med Port 27: 325-330, 2014. PMID: 25017344. DOI: 10.20344/ amp.4784

24 Boffetta P, Merletti F, Winkelmann R, Magnani C, Cappa APM and Terracini B: Survival of breast cancer patients from
Piedmont, Italy. Cancer Causes Control 4: 209-215, 1993. PMID: 8318637. DOI: 10.1007/BF00051315

25 Mitchell KJ, Fritschi L, Reid A, McEvoy SP, Ingram DM, Jamrozik K, Clayforth C and Byrne MJ: Rural-urban differences in the presentation, management and survival of breast cancer in Western Australia. The Breast 15: 769-776, 2006. PMID: 16765049. DOI: 10.1016/j.breast.2006.04.001

26 Istituto Superiore di Sanità: Eurocare 5 Survival Analysis 2000 - 2007. EUROCARE, 2018. Available from: https://w3.iss.it/ site/EU5Results/forms/SA0007.aspx (last accessed February 20, 2018)

$27 \mathrm{Yu}$ XQ, Luo Q, Kahn C, O'Connell DL and Houssami N: Temporal trends show improved breast cancer survival in Australia but widening urban-rural differences. Breast 24: 524527, 2015. PMID: 25843905. DOI: 10.1016/j.breast.2015.03.006

28 Elston CW, Ellis IO and Pinder SE: Pathological prognostic factors in breast cancer. Crit Rev Oncol 31: 209-223, 1999. PMID: 1757079. DOI: 10.1016/S0936-6555(98)80105-2

29 Korhonen T, Kuukasjärvi T, Huhtala H, Alarmo E-L, Holli K, Kallioniemi A and Pylkkänen L: The impact of lobular and ductal breast cancer histology on the metastatic behavior and long-term survival of breast cancer patients. Breast 22, 2013. PMID: 23863867. DOI: 10.1016/j.breast.2013.06.001

30 Rummel S, Hueman MT, Costantino N, Shriver CD and Ellsworth RE: Tumour location within the breast: Does tumour site have prognostic ability? Ecancermedicalscience 9: 552, 2015. PMID: 26284116. DOI: $10.3332 /$ ecancer.2015.552

31 Ufen M-P, Köhne CH, Wischneswky M, Wolters R, Novopashenny I, Fischer J, Constantinidou M, Possinger K and Regierer AC: Metastatic breast cancer: are we treating the same patients as in the past? Ann Oncol 25: 95-100, 2014. PMID: 24276026. DOI: $10.1093 /$ annonc/mdt429

32 International Agency for Research on Cancer - World Health Organization: International Classification of Diseases for Oncology. Third Edition. Geneva, 2013.

33 Aguiar P: Guia Prático Climepsi de Estatística em Investigação Epidemiológica: SPSS, First Edition. Climepsi, Lisbon, 2007.

34 Dawson B and Trapp RG: Basic \& Clinical Biostatistics, Fourth Edition. McGraw-Hill, New York, 2004.

35 Bennett H, Marshall R, Campbell I and Lawrenson R: Women with breast cancer in Aotearoa New Zealand: the effect of urban versus rural residence on stage at diagnosis and survival. $\mathrm{N} \mathrm{Z}$ Med J 120: 1266, 2007. PMID: 18264200.

36 Dijkstra L and Poelman H: Regional working paper 2014: A harmonised definition of cities and rural areas: the new degree of urbanisation (WP01/2014). European Commission, 2014. Available from: https://ec.europa.eu/regional_policy/sources/ docgener/work/2014_01_new_urban.pdf (last accessed April 10, 2018)

37 Nyante SJ, Dallal CM, Gierach GL, Park Y, Hollenbeck AR and Brinton LA: Risk Factors for Specific Histopathological Types of Postmenopausal Breast Cancer in the NIH-AARP Diet and Health Study. Am J Epidemiol 178: 359-371, 2013. PMID: 23899816. DOI: $10.1093 / \mathrm{aje} / \mathrm{kws} 471$

Received July 2, 2019

Revised July 24, 2019

Accepted July 29, 2019 